\title{
Comparative Analysis of Two Energy-Efficient Technologies Used in the Shanghai Tower
}

\author{
Sarah Chen 1 , Yuyang Li ${ }^{2}$ \\ ${ }^{1}$ Western Canada High School, Calgary, Canada \\ ${ }^{2}$ Jinan Xinhang Experimental Foreign Language School, Jinan, China \\ Email: sarah.chenyishan@gmail.com
}

How to cite this paper: Chen, $\mathrm{S}$. and $\mathrm{Li}$, Y.Y. (2022) Comparative Analysis of Two Energy-Efficient Technologies Used in the Shanghai Tower. Energy and Power Engineering, 14, 1-12.

https://doi.org/10.4236/epe.2022.141001

Received: November 26, 2021

Accepted: January 17, 2022

Published: January 20, 2022

Copyright (c) 2022 by author(s) and Scientific Research Publishing Inc. This work is licensed under the Creative Commons Attribution International License (CC BY 4.0).

http://creativecommons.org/licenses/by/4.0/

(c) (i) Open Access

\begin{abstract}
Climate change continues to affect the lives of individuals across the world, creating a rise in demand for new technologies that can slow down the impacts of climate change. Shanghai, one of the largest cities in the world, has one of the highest carbon emission levels. In recent years, the research and development of energy-efficient technologies have gained more and more attention. The Shanghai Tower is a pioneer in green building design and a prominent example of Shanghai's efforts towards low-carbon city development. In this paper, two technologies within the Shanghai Tower-ground source heat pumps (GSHP) and double skin facades (DSF) - will be analyzed. The paper will consist of firstly an investigation of the principles of the technologies, and then analysis, evaluation, and comparison of their respective characteristics. While both GSHP and DSF are used for sustainable purposes, the effectiveness of technologies depends on what environment the technology is used in and what purpose they serve. The evaluation of GSHP and DSF will be based on their performances under Shanghai's climate and whether they contribute to the purposes of the Shanghai Tower.
\end{abstract}

\section{Keywords}

Shanghai Tower, Green Buildings, Ground Source Heat Pump, Double Skin Facade, Energy Efficiency

\section{Introduction}

Shanghai is the second-largest city in China and the third most populous city in the world, with a population of 27.8 million people as of 2021 [1]. Over the past years of rapid development, the municipality now has the highest GDP in China but also one of the largest carbon footprints in the world [2]. As the population 
grows, energy consumption will continue to increase. The city has a subtropical monsoon climate.

The building industry consumes around $40 \%$ of the world's energy and $25 \%$ of global water supply, contributing to $40 \%$ of air pollution, landfill waste, and one-third of global greenhouse gas emissions. Aware of the seriousness of global warming, people are beginning to look for renewable alternatives to current systems.

"Green buildings" refer to buildings that are environmentally friendly at any stage-from their construction process and maintenance mechanisms to their future demolition. These typically use more sustainable types of technology or rely mostly on renewable energy. A crucial aspect of designing sustainable infrastructure is choosing the right technology-solar panels don't function as well as wind turbines in windy climates and all-glass walls aren't be suited for hotels. To measure the effectiveness of the building, standards made by the Leader in Energy and Environmental Design (LEED), and US Green Building Council are used to evaluate and classify the degree to which a building is considered "green".

\section{Methodology}

Shanghai is a leading city in sustainable living initiatives. The recently completed Shanghai Tower is among the tallest, but also most energy-efficient buildings in the world, using forty-three different types of renewable energy technology. The purpose of this paper is to use the Shanghai Tower as a case study and analyze the applications of two types of technology on the tower. The main problem to be discussed is whether GSHP and DFS are effective in reducing energy consumption in the Shanghai Tower. This analysis can then be applied to other tall buildings constructed in climates like that of Shanghai and buildings that share the same functions as the Shanghai Tower.

Analysis of the two technologies will consist of a general overview of their designs and functions, how they help reduce energy consumption, and how they have been implemented into the structure of the Shanghai Tower. As there is no specific agreement with the Shanghai Tower's administration to retrieve unreleased data, all information will be from previously published papers and studies on the Tower as well as any publicly released statistics.

\section{Overview of the Shanghai Tower}

The Shanghai Tower is the second tallest building in the world, standing 632 $\mathrm{m}$ tall with 127 stories. The building is split into nine zones which function as recreational, hotel, office, and retail facilities. Completed in April 2015, the nearly seven-year project contains unprecedented designs and numerous innovations in the city's development towards sustainable infrastructure. The Shanghai Tower cost CNY5.4 billion (approximately 860 million USD) to construct. In September 2012, the tower was awarded the Certificate of Green Building Design, receiving a three-star rating, as well as obtained Leader in Energy and Environmental Design (LEED) Platinum and Gold certifications from the US 
Green Building Council for different aspects of the building. The tower utilizes forty-three green technologies to reduce energy consumption by $21 \%$ and water consumption by $40 \%$, reducing the carbon footprint of the building by 34,000 metric tonnes each year [3]. Major technologies include 270 wind turbines to supply 54,000 kWh of annual renewable energy, a cogeneration system that supplies $2200 \mathrm{~kW}$ of annual electricity, and "intelligent building controls" to monitor and adjust systems in the building. Materials used were locally sourced with high-recycled content. One-third of the site is covered in greenery, which reduces the amount of heat generated from the pavement and is managed using efficient watering methods. Approximately 58 million USD was saved in construction costs [4].

\section{Ground Source Heat Pump}

\subsection{Overview}

The GSHP system, also known as the geothermal heat pump, is a heating and cooling system usually used by commercial buildings and individual houses. It was first developed in North America and Europe, later being developed in China in 2010. China now has the second most GSHP system, the first being the United States. GSHP provides a renewable alternative to conventional energy systems. They should be built in areas where the ground is mainly soil and has a certain depth. The system functions best in subtropical monsoon climates, where there are distinct seasons and no extreme weather.

As shown in Figure 1, the principle of this system uses a heat pump to exchange heat between the underground soil and inside the building. Geothermal stakes are buried underground where the soil has a stable temperature. These stakes are connected to the inside of the building by tubes containing water as the medium of heat transfer. The water is continually recycled between the building and underground. In hot summers, the underground temperature would be cooler than the surrounding air, which cools down the water. It is then transferred to the building, cooling down the air to condition the indoors. The

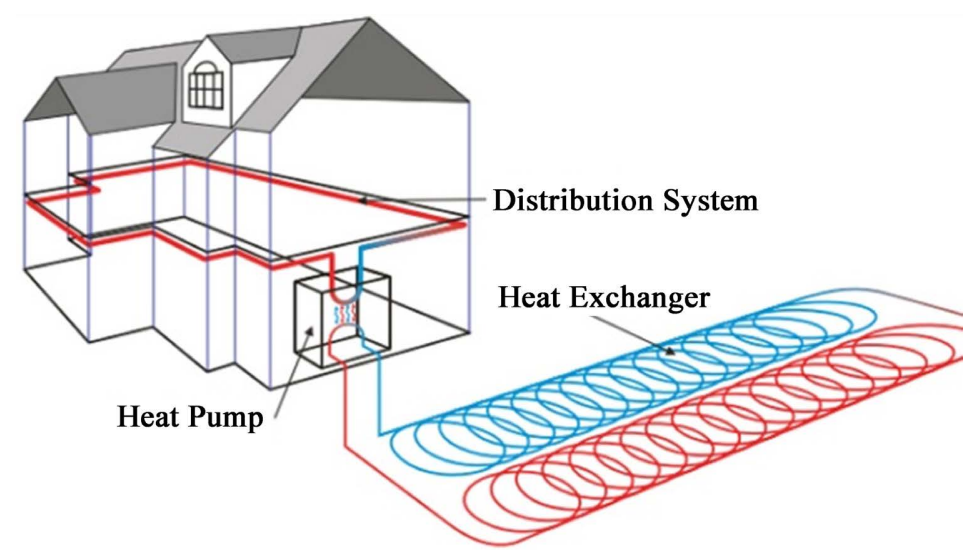

Figure 1. Ground source heat pump components. Retrieved from North Dakota State University Publications [6] 
temperature of the underground will be comparatively opposite in the winter, but it functions in the same way. Underground geothermal water storage tanks are also needed to store water. The GSHP system is normally $40 \%$ more efficient than the traditional air source heating or cooling system. If the system consumes $1 \mathrm{~kW}$ energy, people could receive $4 \mathrm{~kW}$ of heat or cool energy. A well-installed GSHP system could have up to $300 \%-400 \%$ efficiency [5]. The cooling and heating index is about $3.5-4.4,40 \%$ more than traditional air-source heat pump. Since transferring the water from GSHP to the building requires electricity, they will often work in conjunction with other systems in the building which generate renewable energy. Like traditional air conditioning, it supplies the hot or cold air source to achieve a comfortable temperature inside a building or house.

Using ground source power has its unique advantages. Firstly, it reduces the heat expelled by outdoor units into the atmosphere by the traditional air source system, which significantly reduces the air pollution of a building. Secondly, in some buildings, the underground water tanks could also be used in case of a fire. Thirdly, the maintenance cost of GSHP is only $50 \%-60 \%$ of traditional center air-source conditioning systems and can last up to twenty-five years [7]. GSHP are often installed in commercial buildings which are crowded around city center. Since the system does not release any greenhouse gases, it is much safer and cleaner for citizens.

GSHP also has its disadvantage. The GSHP system should be designed before the building construction, and it relates to the utilization of underground space of an infrastructure. Since the GSHP system must be installed as a system, it costs far more than individual air-source units. Additionally, the GSHP system needs to have a pump to transfer water, and have fans to cool down the air, which may cause sound disturbance to people inside the building.

The optimal conditions of the GSHP system are that it could provide all building heating and cooling and do not need an extract system to support it. Also, the cost of this system should be controlled in an acceptable range, and the efficiency should be higher than traditional air source system. It should not cost more electricity than a normal air source system and should not decrease the customer experience of using this system. The best type of building is located above a deep soil area, and the climate is distinct seasons and no extreme weather. It should also have a certain scale, which could afford the whole system price, the system best design before the building construction starts.

\subsection{GSHP in the Shanghai Tower}

Shanghai Tower is a great example of a GSHP system application. The average annual stable temperature in the underground of Shanghai is about $18.8^{\circ} \mathrm{C}$. There are also many geothermal stakes were buried under the building as a heat exchange. The GSHP system of the Shanghai Tower is 390\% more efficient than the traditional air source system. Shanghai has a subtropical monsoon climate, which could enable GSHP system work suitable. The water recycling system, in 
Shanghai Tower, could also cooperate with GSHP system, providing water for the GSHP system

The GSHP system of the Shanghai Tower reduces the heat emission compared to traditional air source systems, reducing the urban heat island effect. Normal air source air conditioning directly exchanges the heat between the surrounding air and inside the building, but geothermal heat pump system allows exchange between underground soil and inside the building without heat emission to the surrounding environment, as shown in Figure 2. This can drastically reduce the amount of energy required to condition the tower as well as the level of greenhouse gas emissions. While traditional air source systems require a significant amount of water to cool down, GSHP in the Shanghai Tower work in conjunction to its rainwater recycling system to use only recycled water and reduce generated wastewater.

As the total energy consumption of GSHP, when it is used for cooling, it will consume $24,257 \mathrm{kWh}$ of electricity. The total energy consumption of Shanghai Tower is around 12 million $\mathrm{kWh}$.

A similar GSHP structure can be found in the Tokyo Skytree in Tokyo, Japan. Like Shanghai, Tokyo has a subtropical climate with two distinct seasons. The heating and cooling system of the building uses a geothermal water source heat pump which works with other renewable energy including solar panels to maximize energy efficiency and minimize greenhouse gas emissions. This is the first example of geothermal energy in Japan. Soil temperatures remain consistent throughout the year, making geothermal energy a reliable method of storing water. Japan is also making efforts to expand GSHP to larger-scale buildings rather than only in individual houses [9]. Compared to the Tokyo Skytree, the GSHP in the Shanghai Tower is of a much larger scale. Both buildings are able to

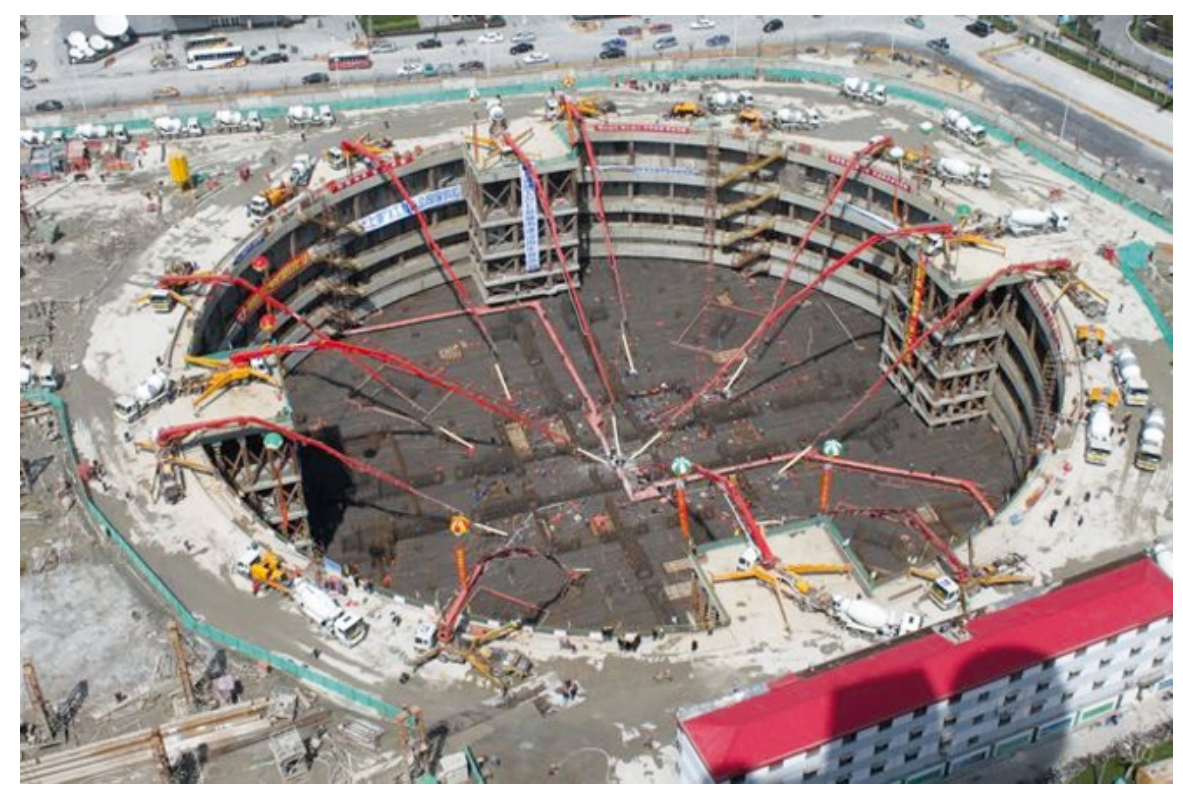

Figure 2. Shanghai Tower underground construction site. Retrieved from ZWP Ingenieur-AG [8]. 
use geothermal power and GSHP in conjunction with other sustainable technologies.

\subsection{Future Prospects}

New GSHP systems use energy that can be drawn from both the air and ground. As well, traditional GSHP work more efficiently in warmer climates, which limits the locations that can implement these systems. This means that future GSHP technology should be developed to have similar efficiency levels in both cold and warm weather, and so that the material is able to cope with freezing temperatures. New technological advancements allow automatic detection of temperature around the building, which can adjust the amount of necessary heat transferred to different parts of the building, increasing occupant comfort and maximizing energy savings.

\section{Double Skin Facade}

\subsection{Types of Double Skin Facades}

DSF refers to a variety of systems consisting of two layers of glazed glass walls separated by an atrium. Typically used for taller commercial buildings, the main benefits of DSF include improving natural lighting during the day and reducing overall energy consumption. DSF is categorized depending on the air ventilation in the interior of the building, airflow within the cavity, as well as how the cavities are divided throughout the building [10].

Early cavity designs were "buffer zones" that protected the interior from outside weather and sound. These are classified as "buffer facades", shown in the image on the left in Figure 3. The atrium allows for conditioning without the air flow interfering with the indoor space. The cavity width ranges between 250 to
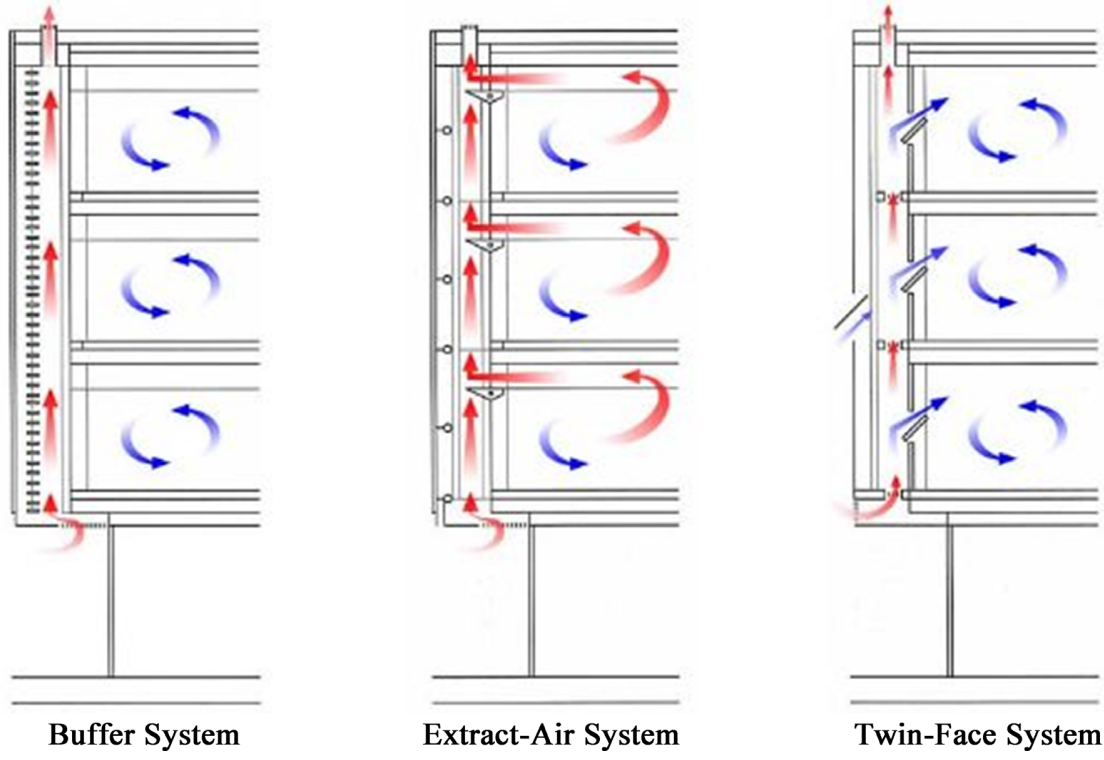

Figure 3. Direction of airflow in common types of DSF systems. Retrieved from University of Waterloo [10]. 
$900 \mathrm{~mm}$. The space is sealed from the inside which means there need to be additional air conditioning systems to bring the air inside. Fresh air travels from the building's base through an air conditioning system that circulates into the building. Exhaust air is then released from the top of the building.

In areas where buildings must be sealed from the environment, the atrium can be part of the air conditioning system, known as "extract air facades", as shown in the middle image in Figure 3. The atrium allows exhaust air to leave the building. While this prevents natural ventilation, it can increase insulation using warmed exhaust air in the cavity. These rely solely on mechanical ventilation and don't significantly reduce energy consumption. The inner wall is typically insulated double-glazed glass and the outer is single glazed. The structure is like buffer facades.

For natural air ventilation, a "twin system facade" is implemented, as shown in the image on the right in Figure 3. The outer layer is single-layer insulated or laminated glass skin that provides protection and the inner double-glazed layer provides insulation [11]. The width of the atrium has a great degree of flexibility as long as it allows for cleaning and maintenance. Openings in each layer create airflow between the interior and the atrium, but it runs the risk of decreased insulation if the outer layer is not well-sealed. Twin face systems can circulate a larger amount of air through the atriums, expelling warmed-up exhaust air out into the atmosphere more efficiently.

Further classification of DSF can be dependent on the type of airflow and the way in which the air space is divided. Airflow between the air cavity can be mechanical, natural, or hybrid. Most facade designs allow for a hybrid type of airflow, where mechanical airflow is used to drive the natural ventilation. Shades may be added in the cavity to reduce solar glare and for accessible cleaning in any design. Recent designs strive towards maximizing natural ventilation to reduce electricity consumption and save energy within the building.

\subsection{Pros and Cons of DSF}

Primary benefits of DSF are attributed to reducing ventilation requirements on the building's HVAC systems. The mechanisms in which facades do so depend on their structural design and environment. The glass maximizes the amount of solar energy entering the building and the number of hours of natural sunlight. DSF provides a second layer of protection for external forces including sound, wind, or air pollution. Access to natural daylight and a workspace without glare ensures the comfort of occupants.

The benefits of DSF come at quite a high cost. DSF can be up to five times as expensive as regular cladding structures due to the extra construction, maintenance, and material costs [12]. At the same time, the atriums decrease the amount of available space. While the Shanghai Tower uses the atriums as gardens, the space can no longer be rented out and be used for business purposes. The airflow in the atriums moves at a higher velocity than the air inside the 
building due to the constant ventilation in a smaller space. This could result in discomfort for occupants, and potentially be dangerous in the case of a fire. Not much information is available on the performance of DSF under fires, but a poor design could allow for rapid spread of smoke throughout the building if a fire were to arise.

\subsection{DSF in the Shanghai Tower}

The Shanghai Tower has a unique DSF design. The overall shape is an equilateral triangle, and the outer skin has a $120^{\circ}$ rotation. The size of the top of the building is $55 \%$ of the lower part to counter air turbulence and typhoon-level winds at higher altitude. The outer layer is insulated glass while the inner layer is laminated glass. The tapering atrium between the glass layers is a space for air ventilation and insulation, allowing air in and out of the building without disrupting the inside. The Shanghai Tower is among the first buildings to have the atrium as a useable space, a public garden. The outer wall is supported by horizontal pipes connected to rods hung from the top of each zone. The cavity is horizontally divided only between each zone to optimize the use of natural airflow.

From zones one to eight, the cavity is further split into three layers of atria. Although each atrium cannot rely completely on natural ventilation, there is

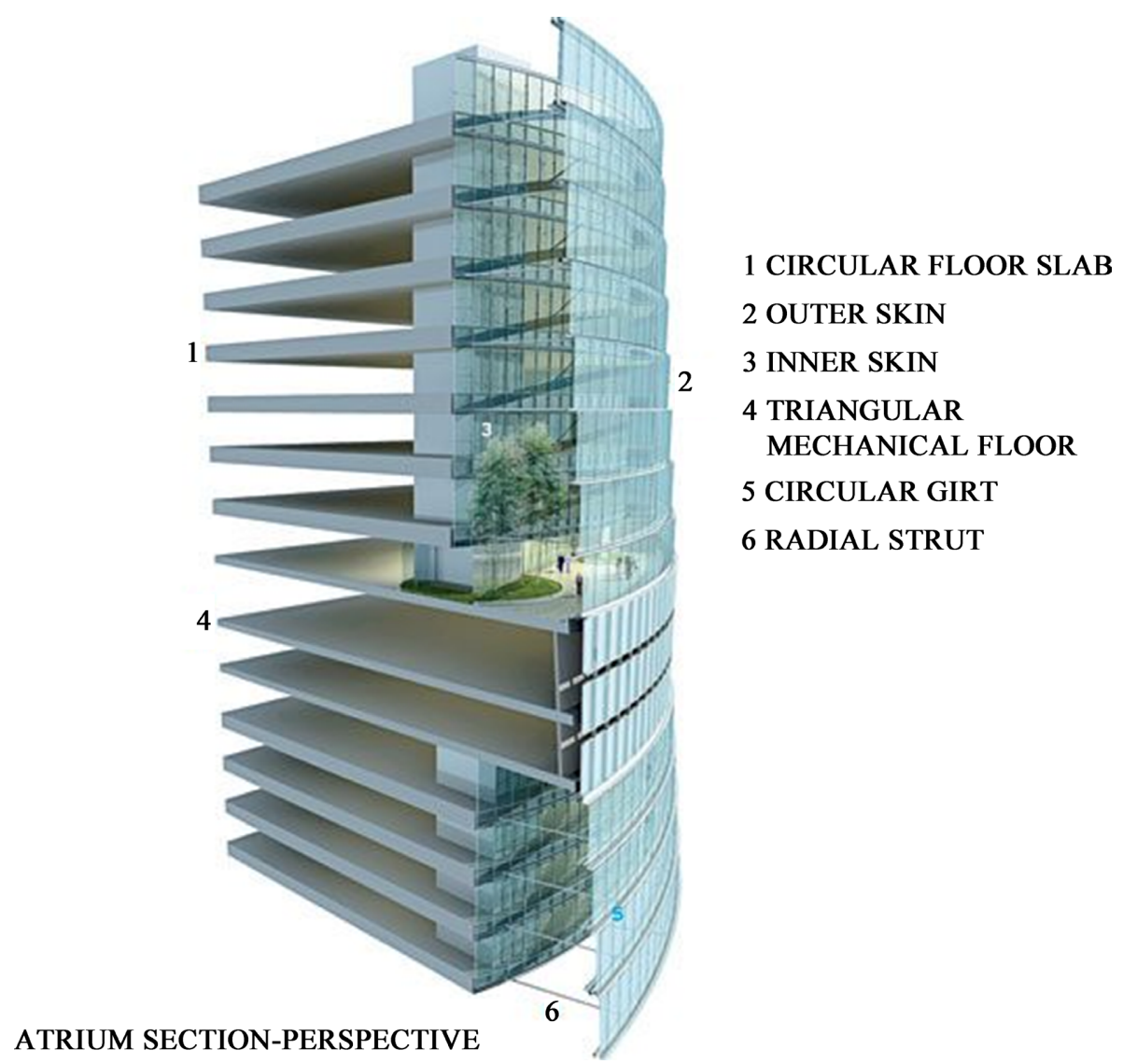

Figure 4. Facade of the Shanghai Tower. Retrieved from Gensler [13]. 
minimal artificial conditioning. A fan coil unit is the foundation of the heat ventilation and air conditioning (HVAC) system to condition the first fifteen feet of each atrium, and the remaining space is run on natural airflow. Only in extreme weather will they rely more on the HVAC system. The bottom and top of each atrium has regulated exhausts. In the winter, air that enters the bottom exhaust is heated and then distributed into office space. As the air circulates around the office, it is then released into the atrium between walls $A$ and $B$ and then updrafts to the top regulated exhaust so that it can be released back into the atmosphere. When necessary, there is artificial heating provided around the interior perimeter of the outer wall, which is labeled 2 in Figure 4.

The atrium between walls $\mathrm{A}$ and $\mathrm{B}$ is used as a public garden. To meet city code while also creating a healthy environment for greenery, wall A has an encloser for unconditioned and ventilated air, while wall $\mathrm{B}$ is the actual exterior. Overall, the building creates $21 \%$ energy efficiency, $7 \%$ of which is from the DSF design.

Facades have been used in large office and commercial buildings for decades. Structures such as the One Angel Square in Manchester and 30 St Mary Axe in London, United Kingdom. Both buildings have around 50\% of energy savings with curved walls to make the building more aerodynamic and wind-resistant. Both London and Manchester have an oceanic climate with frequent rainfall, mild summers, and cold winters. DSF is suitable in a wide range of climates as the atrium can adapt to the required temperature as long as there is no extreme weather [14] [15]. Because the Shanghai Tower is much taller than both buildings in the UK, the air ventilation system will have to be split into different sections depending on the function of the part of the building. As the Shanghai Tower was built more recently, it uses more innovative strategies to utilize the atriums space.

\subsection{Future Prospects}

Demand for DSF has risen due to the increasing need for occupant comfort and noise protection. Future improvements and developments on DSF may include making the facade more lightweight, allowing increased glass piece sizes, and maximizing the functional space in the atria. As more buildings utilize this technology, facades will also have to adapt to the desires of the designer, with flexibility in shape, size, opacity, and material. Models and simulations are able to test the performance of different materials and structures during the designing process. To make DSF more accessible, the construction, maintenance, and cleaning costs will have to reduce dramatically.

\section{Comparing the Two Technologies}

Table 1 shows a comparison of a few properties attributed to DSF and GSHP, offering a visual representation of the following description. The table can be used to evaluate the two technologies in the Shanghai Tower and explain the 
Table 1. Comparison table between ground source heat pumps and double skin facades.

\begin{tabular}{lll}
\hline Property & GSHP & DSF \\
\hline Source of energy & Geothermal energy & Solar energy \\
Areas for & Installation cost $90-150 \mathrm{USD} / \mathrm{m}^{2}$ & Standard installation: $700-950 \mathrm{USD} / \mathrm{m}^{2}$ \\
spending & $1.7 \mathrm{USD} / \mathrm{m}^{2}$ summer operation costs & $\begin{array}{l}\text { Extra costs apply if adding other structures (e.g. Shading } \\
\text { devices) }[16]\end{array}$ \\
& $3 \mathrm{USD} / \mathrm{m}^{2}$ winter operation costs & $35+\mathrm{USD} / \mathrm{m}^{2}$ maintenance and cleaning costs \\
& Other maintenance and cleaning costs are & $10 \mathrm{USD} / \mathrm{m}^{2}$ annual heating and cooling costs \\
required & $7 \%$ in Shanghai Tower \\
Energy efficiency & Max: $21 \%$ General:12\% & Areas with ample sunshine \\
Suitable climates & Deep soil areas, mild weather & None \\
Greenhouse gases & None &
\end{tabular}

mechanisms for how they use the environment to optimize the technologies' purposes in the building. It is crucial to take into considerations the conditions in which GSHP uses geothermal energy while DSF uses solar energy. The difference in sources of energy affects the effective operating hours of the technology. As shown in Table 1, Geothermal energy is available throughout the day, making the GSHP an effective method for air conditioning. Solar energy, on the other hand, makes it more dependent on artificial conditioning. While DSF are most effective in natural air ventilation, it is oftentimes not possible due to the stronger winds in Shanghai and the high altitudes of the building. As a result, DSF in the Shanghai Tower functions mostly to improve access to natural lighting and provide a space for artificial air ventilation away from people in the building. Regardless, both GSHP and DSF work well under Shanghai conditions, with the city's ample amount of sunlight and steady monsoon climate.

Although DSF and GSHP are environmentally friendly, the use of these two technologies creates a significantly greater burden on the financial capacity of the construction of the building. A central goal in constructing the Shanghai Tower was to design one of the most energy-efficient high-rise towers to date, so although greener building options are more expensive, the extra costs are necessary for the building to align with the city's sustainable living initiatives. As shown in Table 1, GSHP designs are generally standard, with larger systems costing more money. DSF is among the most expensive glazed walls to construct due to the extra cost of glass and maintenance, as well as the reduced living spaces [17]. As a result, it is difficult to calculate the exact costs for the DSF. The Shanghai Tower has shading elements in its atriums and additional mechanisms for artificial conditioning. The large size of the tower also makes cleaning and maintaining the facade most expensive than other commercial buildings. The two technologies function to save energy consumption rather than create energy for the building. DSF and GSHP have different operating mechanisms, but they both provide necessary sources of energy for the building.

Depending on the conditions of the surrounding environment, the effectiveness of technologies may be affected. DSF are not suited for extremely cold 
weather or areas with very little sunlight. GSHP systems work best under stable conditions with no extreme weather and must be built in areas with deep soil. DSF can be used in a more diverse range of conditions, as the design of the facade can be altered to meet the needs of the environment; from the size, shape, and height of the atrium to the structural element added for shading, the functions of the DSF can be determined by designers. Regardless of GSHP or DSF, neither technology releases emissions into the atmosphere or directly generates greenhouse gases. The suitability of these technologies also depends on the purpose of the building. Although most customers of GSHP are individuals, there are also many republic buildings that use GSHP system, and the Shanghai Tower proves to be an example of a successful implementation of GSHP.

\section{Conclusions}

By comparing the way GSHP and DSF create sustainable sources of renewable energy, an evaluation can be conducted on the way the Shanghai Tower has pioneered the new generation of green infrastructure and provides new directions for further sustainable development.

The GSHP system mainly serves to provide heating and cooling air source for the whole structure. Shanghai's climates provide conditions that allow for optimal performance of the system. It cooperates with the rainwater recycling system and helps to cool down the equipment in the building. These features allow the tower to be among the most sustainable buildings in the world. Future research would seek to improve exploration, drilling, and assessment technologies, as well as use more modern power grids to reduce cost and increase efficiency.

The DSF in the Shanghai Tower is a complex structure that accommodates the various functions of the building. The tower effectively utilizes the versatility of DSF to design an outer layer that reduces surrounding impacts, an atrium that functions as both a space for ventilation and indoor garden, and an overall system that decreases energy consumption. As well, the tower takes advantage of its glass facade at higher altitudes as tourist attractions. Future analysis on DSF would be focused on finding cheaper options for constructing and maintaining the facade, as well as further ways to optimize the use of the atriums.

\section{Conflicts of Interest}

The authors declare no conflicts of interest regarding the publication of this paper.

\section{References}

[1] (n.d.) Shanghai, China Metro Area Population 1950-2021. Macrotrends. https://www.macrotrends.net/cities/20656/shanghai/population\#:\%7E:text=Shangh ai\%20-\%20Historical\%20Population\%20Data\%20\%20\%20

[2] Yang, Y.T., Qu, S., Cai, B.F., Liang, S., Wang, Z.H., Wang, J.N. and Xu, M. (2020) Mapping Global Carbon Footprint in China. Nature Communications, 11, Article No. 2237. https://doi.org/10.1038/s41467-020-15883-9 
[3] Continuing Education: Double-Skin Buildings (n.d.).

https://www.architecturalrecord.com/articles/5911-continuing-education-double-sk in-buildings

[4] Lau, G.L. (2015) Sustainable High-Rise Construction in Shanghai. University of Lisbon, Lisbon.

[5] Ground Source Heat Pump Association (n.d.) Domestic Ground Source Heat Pumps. GSHPA, London.

https://www.gshp.org.uk/ground_source_heat_pumps_Domestic.html

[6] Pedersen, C. (2018) Ground-Source Heat Pumps. North Dakota State University, Fargo. https://www.ag.ndsu.edu/publications/energy/ground-source-heat-pumps

[7] Ground Source Heat Pump Association (n.d.) Ground Source Heat PumpsCommercial. GSHPA, London. https://gshp.org.uk/Ground_Source_Heat_Pump.html

[8] (n.d.) Shanghai Tower, China. ZWP Ingenieur-AG. https://www.zwp.de/en/references/office-buildings/shanghai-tower-china/

[9] Babasaki, T. (n.d.) Tokyo Skytree Town: Where the Environment and Tourism Are One.

https://www.metro.tokyo.lg.jp/english/about/tokyo/documents/tokyo_brochure_15 1.pdf

[10] Boake, T.M., Harrison, K., Collins, D., Chatham, A. and Lee, R. (2003) Understanding the General Principles of the Double Skin Facade System. University of Waterloo, Waterloo.

[11] Pollard, B. (2009) Double Skin Facades-More Is Less? Environment Design Guide, 1, 1-10. https://www.jstor.org/stable/26151881

[12] (n.d.) Shanghai Tower Facts and Information. The Tower Info. https://thetowerinfo.com/buildings-list/shanghai-tower/

[13] (n.d.) Shanghai Tower. Gensler. https://www.gensler.com/projects/shanghai-tower

[14] The Gherkin: How London's Famous Tower Leveraged Risk and Became an Icon (Part 2). ArchDaily. https://www.archdaily.com/447205/the-gherkin-how-london-s-famous-tower-lever aged-risk-and-

[15] (n.d.) One Angel Square, Co-Operative Group HQ, Manchester. BREEAM. https://www.breeam.com/case-studies/offices/one-angel-square-co-operative-group -hq-manchester/

[16] Tam, V.W.Y., Le, K.N. and Wang, J.Y. (2018) Cost Implication of Implementing External Facade Systems for Commercial Buildings. Sustainability, 10, Article No. 1917. https://doi.org/10.3390/su10061917

[17] Davison, N. (2013) Is the Shanghai Tower the World's First Eco-Friendly Skyscraper? China Dialogue.

https://chinadialogue.net/en/cities/6413-is-the-shanghai-tower-the-world-s-first-ec o-friendly-skyscraper/ 